\title{
Lanthanide Paramagnetic Probes for NMR Spectroscopic Studies of Fast Molecular Conformational Dynamics and Temperature Control. 18-Crown-6 Intramolecular Reorientation in Complexes of Cerium(III) Chelates
}

\author{
Sergey P. Babailov, and Anna V. Goryunova \\ A.V. Nikolaev Institute of Inorganic Chemistry SB RAS, 630090 Novosibirsk, Russia \\ E-mail: babajlov@niic.nsc.ru
}

\begin{abstract}
By ${ }^{1} \mathrm{H}$ dynamic NMR method the conformational reorientation of the 18 -crown-6 ether molecules in $\left[\left(\mathrm{Ce}(\mathrm{ptfa})_{3}\right)_{2}(18-\right.$ crown-6)] complexes has been experimentally studied in the $\mathrm{CDCl}_{3}$ solution. The results of the present work demonstrate that there is a conformational dynamic processes in $\left[\left(\mathrm{Ce}(\mathrm{ptfa})_{3}\right)_{2}(18\right.$-crown-6)] complex (with the activation free energy $\left.\Delta G^{*}(320 \mathrm{~K})=49 \pm 4 \mathrm{~kJ} / \mathrm{mol}\right)$. It is conditioned by conformational reorientation of 18-crown-6 molecule. These complexes are promising to be subnanoscale NMR spectroscopic probes to determine the temperature in nonaqueous media.
\end{abstract}

Keywords: Lanthanide-induced shifts, lanthanides, paramagnetic lanthanide complexes, magnetic resonance thermometric sensors, chelate ligands, crown ethers, nonaqueous solutions, conformational dynamics.

\section{Introduction}

During last decades, an increase in the number of publications devoted to the molecular structure and to the dynamics of the rare earth coordination compounds has been observed. ${ }^{[1-11]}$ The information about the molecular structure and the dynamics of the rare earth coordination compounds in solutions underlies the existing technologies for the photoresists production in microelectronics, sensitizers for photodynamic therapy, contrast reagents for magnetic resonance imaging (MRI), synthetic models of natural ionofores, and sensors for biology and medicine. ${ }^{[11-23]}$

Over the past 10 years there has been a resurgence of interest in the coordination chemistry of lanthanide complexes in solution. A renewed interest in this work may be connected with an enhanced appreciation of the rich functionality of lanthanide complexes. The high-spin paramagnetism and long electronic relaxation time of $\mathrm{Gd}^{3+}$ have made it pre-eminent among contrast agents for magnetic resonance imaging. ${ }^{[26-29]}$ Related complexes of many other lanthanide cations with much shorter electronic relaxation times are effective NMR lanthanide shift reagents. ${ }^{[18,29]}$ It should be noted that we solve the problem of the substrate molecule intramolecular dynamics study with the help of the paramagnetic probe application. It is used for studying the conformational dynamics of such polydentate complex reagents as crown ethers in nonaqueous solutions. Previously, the advantages of this approach's application for paramagnetic complexes were discussed in comparison with DNMR studies of the diamagnetic substances. ${ }^{[18,29]}$ In particular, the relative ranges of the chemical exchange rate constants to be measured were considered. As a result of paramagnetic chemical shifts in $4 f$ complexes, the range of measurable rate constants expands considerably compared to the analogous range in the diamagnetic compounds. ${ }^{[18,29]}$

Studies of paramagnetic chemical shifts in NMR spectra allow us to gain qualitative and quantitative information about the molecular structure as well as the kinetic and thermodynamic stability of paramagnetic complexes in solutions. ${ }^{[11-23]}$ Recently, the growth of interest in studies of lanthanide $(\mathrm{Ln})$ cations with macrocyclic ligands (in particular with macrocyclic polyethers (MCPE) $)^{[5-16,18,24-25]}$ has been noticed. MCPE are promising to be extractants and NMR analytical reagents and are regarded by many researchers as model compounds for natural ionophores. ${ }^{[18]}$ The lanthanide salt complexes of the cerium subgroup with 18-membered macrocyclic polyethers are compounds, for which the possibility of forming coordination saturated 12-coordinated inclusion complexes of the lanthanides has been found. ${ }^{[1-4,18]}$ Presently, the thermodynamic, structural and electronic properties of 18-membered macrocyclic ether complexes with the lanthanide cations are well known both in the solution and in the solid state. ${ }^{[5-16,18,24-25]}$

Earlier we studied the thermodynamic stability, molecular structure and the intramolecular dynamics of tris-1,1,1-trifluoro-5,5-dimethyl-2,4-hexanedionato (ptfa) lanthanides with MCPE 18-crown-6 interaction products in dependence on Ln cation atomic number. It has been found, that in case of heavier Ln (Gd, Tb, Dy, Ho, Er, Yb), when $\left[\mathrm{Ln}(\mathrm{ptfa})_{3}\left(\mathrm{H}_{2} \mathrm{O}\right)\right]$ interacting with crown ether 18-crown-6 in $\mathrm{CDCl}_{3}, \mathrm{CD}_{2} \mathrm{Cl}_{2}$ and $d_{8}$-toluene solutions, the kinetically unstable complexes with the ratio $1: 1[\operatorname{Ln}(18$-crown- 6$)$ $\left.(\mathrm{ptfa})_{3}\right] \cdot \mathrm{H}_{2} \mathrm{O}$ are formed (it has been established by studying magnitudes of chemical shifts in ${ }^{1} \mathrm{H}$ and ${ }^{19} \mathrm{~F}$ NMR spectra on MCPE, ptfa and $\mathrm{H}_{2} \mathrm{O}$ molecule nuclei in dependence on 
base reagents concentrations). ${ }^{[18]}$ The found magnitudes of thermodynamic stability constants are $17 \pm 4 \mathrm{M}^{-1}$.

The LIS temperature dependence on Ln cation magnetic properties analysis has shown the 1:1 complex isostructurality. But in case of lighter $\mathrm{Ln}$, when $\left[\mathrm{Ln}(\mathrm{ptfa})_{3}\left(\mathrm{H}_{2} \mathrm{O}\right)\right]$ interacting with 18-crown-6 in solutions, the complex ion pairs (IP) $\left[\mathrm{Ln}\left(18 \text {-crown-6) }(\mathrm{ptfa})_{2}\right]^{+}\left[\mathrm{Ln}(\mathrm{ptfa})_{4}\right]^{-} \mathrm{nH}_{2} \mathrm{O}\right.$ in addition to other reaction products are formed (where $\mathrm{Ln}=\mathrm{La}, \mathrm{Ce}, \mathrm{Pr}, \mathrm{Nd}$ and $\mathrm{Eu}) .{ }^{[18]}$ It should be noted, that the possibility of [ $\mathrm{Ln}(18-$ crown-6)(ptfa $\left.)_{2}\right]^{+} \cdot\left[\mathrm{Ln}(\mathrm{ptfa})_{4}\right]^{-} \cdot \mathrm{nH}_{2} \mathrm{O}$ IP formation in solution is in good agreement with the later results in the work by K.D. Pollard, where the possibility of formation of $\left[\mathrm{Y}(\mathrm{hfa})_{2}\right.$ (tetraglyme $)]^{+}\left[\mathrm{Y}(\mathrm{hfa})_{4}\right]^{-}$IP when interacting tris- $\beta$-diketonates $\mathrm{Y}$ with relative to crown ethers noncyclic poly-ethers (glymes) was found. ${ }^{[18]}$ Moreover, it was experimentally found by NMR method that the IP cation fragments have the structure of inclusive type.

Complex formation thermodynamics of $\left[\operatorname{Ln}(\mathrm{ptfa})_{3}\right]-$ (18-crown-6) system in the framework of our model was described by thermodynamic Equations 1-3. ${ }^{[25]}$

$$
\begin{aligned}
& \left\{\left[\mathrm{LnL}_{3}\left(\mathrm{H}_{2} \mathrm{O}\right)_{2}\right]\right\}_{\text {solv }}+\mathrm{S}_{\text {solv }} \stackrel{\mathrm{K}_{1}}{\Leftrightarrow}\left\{\left[\mathrm{LnL}_{3} \mathrm{~S}\right] \cdot 2 \mathrm{H}_{2} \mathrm{O}\right\}_{\text {solv }} \\
& \left.\left\{\left[\mathrm{LnL}_{3} \mathrm{~S}\right] \cdot 2 \mathrm{H}_{2} \mathrm{O}\right]\right\}_{\text {solv }}+\left\{\mathrm{LnL}_{3}\left(\mathrm{H}_{2} \mathrm{O}\right)_{2}\right\}_{\text {solv }} \stackrel{\mathrm{K}_{2}}{\Leftrightarrow} \\
& \left\{\left[\left(\mathrm{LnL}_{3}\right)_{2} \mathrm{~S}\right] \cdot 4 \mathrm{H}_{2} \mathrm{O}\right\}_{\text {solv }} \\
& \left.\left\{\left[\mathrm{LnL}_{3} \mathrm{~S}\right] \cdot 2 \mathrm{H}_{2} \mathrm{O}\right]\right\}_{\text {solv }}+\left\{\mathrm{LnL}_{3}\left(\mathrm{H}_{2} \mathrm{O}\right)_{2}\right\}_{\text {solv }} \stackrel{\mathrm{K}_{3}}{\Leftrightarrow} \\
& \left\{\left[\mathrm{LnL}_{2} \mathrm{~S}\right]^{+}\left[\mathrm{LnL}_{4}\right]^{-} \cdot 4 \mathrm{H}_{2} \mathrm{O}\right\}_{\text {solv }}
\end{aligned}
$$

Here $\mathrm{L}$ is ptfa and $\mathrm{S}$ is (18-crown-6). The constant of equilibrium $K_{1}$ of $\left[\left(\mathrm{Eu}(\mathrm{ptfa})_{3}\right)(18\right.$-crown-6)] complex formation is $470 \pm 130$. As we supposed $K_{1}$ equals to constant of equilibrium $K_{2}$ of $\left[\left(\mathrm{Eu}(\mathrm{ptfa})_{3}\right)_{2}(18\right.$-crown-6) $]$ complex formation. ${ }^{[25]}$ Thus, in case of Ce subgroup the $\left[\left(\operatorname{Ln}(\mathrm{ptfa})_{3}\right)\right.$ (18-crown-6)] complex stability constant is larger compared to the stability constants for the Yttrium subgroup complexes. The constant of equilibrium $K_{3}$ of complex formation is $23 \pm$ 4 (in case $\mathrm{Ln}=\mathrm{Eu})$.

In spite of molecular dynamic and structure studying in detail in complex $\left[\mathrm{Ln}(\mathrm{ptfa})_{2}(18 \text {-crown-6) }]^{+}\left[\mathrm{Ln}(\mathrm{ptfa})_{4}\right]^{-}\right.$ $\cdot 4 \mathrm{H}_{2} \mathrm{O}$ IP the other system components, which are in the solution $\left(\left[\operatorname{Ln}(18 \text {-crown-6)(ptfa })_{3}\right]\right.$ and $\left[\left(\operatorname{Ln}(\mathrm{ptfa})_{3}\right)_{2}(18-\right.$ crown-6) $]^{[25]}$ ) are less studied (in case $\mathrm{Ln}=\mathrm{La}, \mathrm{Ce}$, Pr and $\mathrm{Eu})$. In particular, the molecular dynamic in $\left[\left(\mathrm{Ln}(\mathrm{ptfa})_{3}\right)_{2}(18-\right.$ crown-6)] solution is not studied yet (where $\mathrm{Ln}=\mathrm{La}, \mathrm{Ce}, \mathrm{Pr}$ and $\mathrm{Eu}$ ). That is the reason us to continue ${ }^{1} \mathrm{H}$ NMR studying the complex system on the example of $\left[\left(\mathrm{Ce}(\mathrm{ptfa})_{3}\right)_{2}(18-\right.$ crown-6)] complex conformational dynamics.

\section{Experimental}

Samples for NMR spectroscopy were prepared by dissolving $\left[\mathrm{Ce}(\mathrm{ptfa})_{3} \mathrm{H}_{2} \mathrm{O}\right]$ and (18-crown-6) in deuterated chloroform. ${ }^{1} \mathrm{H}$ NMR spectra were recorded using Avance-III-500 and MSL 300 Bruker spectrometers operating at 500 and $300 \mathrm{MHz}$ Larmor frequencies, respectively. The spectra were calibrated by assigning the residual chloroform signal at $298 \mathrm{~K}$ to a shift from TMS of 7.24 ppm 1,4,7,10,13,16-hexaoxacyclo-octadecane (18-crown-6) produced by Cherkasskiy firm (mark 'pure', specification number 6-09-09-190-83) was used. Fourier-transformed spectra were subjected to the complete line shape analysis ${ }^{[18]}$ to obtain rate data for $\left[\left(\mathrm{Ce}(\mathrm{ptfa})_{3}\right)_{2}(18\right.$-crown-6)]. The solution temperature was controlled by using a Bruker B-VT-1000 packaged temperature controller (accuracy $\pm 1 \mathrm{~K}$ ). Temperature calibration was carried out using ethylene glycol and methanol samples.

The start complexes $\left[\mathrm{LnL}_{3} \cdot \mathrm{H}_{2} \mathrm{O}\right]$ were synthesised by known method. ${ }^{[7]}$ The $\left[\mathrm{LnL}_{3} \cdot \mathrm{H}_{2} \mathrm{O}\right]\left(C_{\mathrm{L}}\right)$ and 18-crown-6 $\left(C_{\mathrm{S}}\right)$ concentrations were $C_{\mathrm{L}}=0.2 \div 4 \cdot 10^{-2} \mathrm{M}$ and $10^{-2} \mathrm{M}$, respectively $(\mathrm{L}=\mathrm{ptfa})$.

The isotropic LISs $\left(\Delta \delta_{\text {LIS }}\right)$ in NMR spectra on ligand nuclei and resulting from association of the ligand with the paramagnetic cation were expressed as the sum of diamagnetic shifts $\left(\Delta \delta^{\text {dia }}\right)$ and paramagnetic shifts $\left(\Delta \delta_{\text {LIS }}\right.$ para $):{ }^{[18,25]}$

$$
\Delta \delta_{\text {LIS }}=\Delta \delta^{\text {dia }}+\Delta \delta_{\text {LIS }}^{\text {para }}
$$

The temperature dependence of the LIS was taken into account by extrapolation ${ }^{[18,25]}$ of the low-temperature dependence to the intermediate- and fast-exchange regions (NMR time scale) according to the Curie-Weiss law. ${ }^{[18,25]}$ We have taken into account the temperature dependence of LISs by applying the Curie-Weiss approximation $^{[18,25]}$ during examination of the NMR signal shape temperature dependence.

Required for NMR signal shape analysis, LIS values of exo and endo proton signals "without exchange" in the cases of intermediate and fast exchange (NMR time scaling ${ }^{[18,25]}$ ) were calculated as

$$
\Delta \delta_{\mathrm{i}}(\mathrm{T})=\Delta \delta_{\mathrm{i}}\left(\mathrm{T}_{0}\right)(1 / \mathrm{T}+A) /\left(1 / \mathrm{T}_{0}+A\right),
$$

where $A$ is a constant defined by analysis of the average LIS value for the $-\mathrm{CH}_{2}$ - groups and $\mathrm{T}_{0}=295 \mathrm{~K}$.

The rate constants of the intramolecular dynamics were evaluated by the complete band-shape method for a degenerated two-site exchange. ${ }^{[18,25,29]}$ The first-order rate constant $k$ for the intramolecular exchange process was determined by the comparison of calculated and observed ${ }^{1} \mathrm{H}$ NMR spectra using the home-made LabVIEW 6 program. Activation parameters were determined using the Eyring kinetic Equation 6 from weighted least squares $\{\ln [k(\mathrm{~T}) / \mathrm{T}] v s .1 / \mathrm{T}\}$ where $\mathrm{R}$ is the gas constant, $k_{\mathrm{B}}$ is the Boltzmann constant and $h$ is the Planck constant.

$$
\ln (k / \mathrm{T})=-\Delta G^{\ddagger} / R \mathrm{~T}+\ln \left(\boldsymbol{K} k_{\mathrm{B}} h\right)
$$

where $k$ is the rate constant of chemical exchange reaction, $\mathrm{T}$ is the absolute temperature, and $\boldsymbol{K}$ is the transmission coefficient.

\section{Results and Discussion}

As one can see in Figure 1, experimental LIS values are well approximated by the linear dependence on $1 / \mathrm{T}$, and on the diagram, the average values for exo and endo protons correspond to the $-\mathrm{CH}_{2}-$ groups.

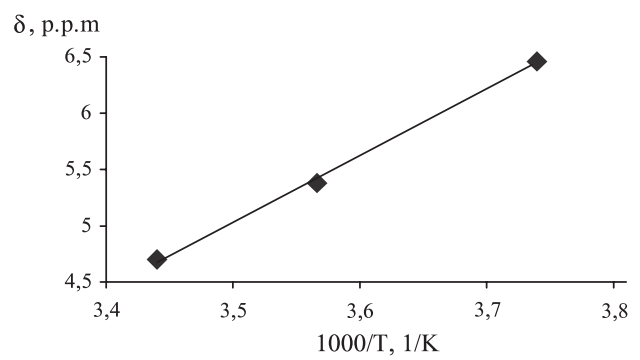

Figure 1. Temperature dependence of the paramagnetic LISs (-CHgroup of ptfa) in $500 \mathrm{MHz}{ }^{1} \mathrm{H}$ NMR spectra of $\left[\left(\mathrm{Ce}\left(\mathrm{ptfa}_{3}\right)\right)_{2}(18-\right.$ crown-6)] with $\mathrm{CDCl}_{3}$ as the solvent; chemical shifts values are relative to diamagnetic $\left[\left(\mathrm{La}(\mathrm{ptfa})_{3}\right)_{2}(18\right.$-crown-6)] complex. 


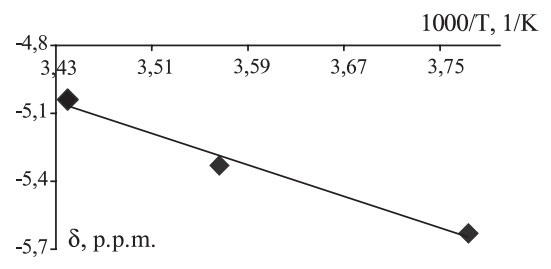

Figure 2. Temperature dependence of the paramagnetic LISs $\left(-\mathrm{CH}_{2}\right.$ - group of 18-crown-6) in $500 \mathrm{MHz}{ }^{1} \mathrm{H} \mathrm{NMR}$ spectra of $\left[\left(\mathrm{Ce}(\mathrm{ptfa})_{3}\right)_{2}\left(18\right.\right.$-crown-6)] with $\mathrm{CDCl}_{3}$ as the solvent; chemical shifts values are relative to diamagnetic $\left[\left(\mathrm{La}(\mathrm{ptfa})_{3}\right)_{2}(18\right.$-crown-6) $]$ complex.

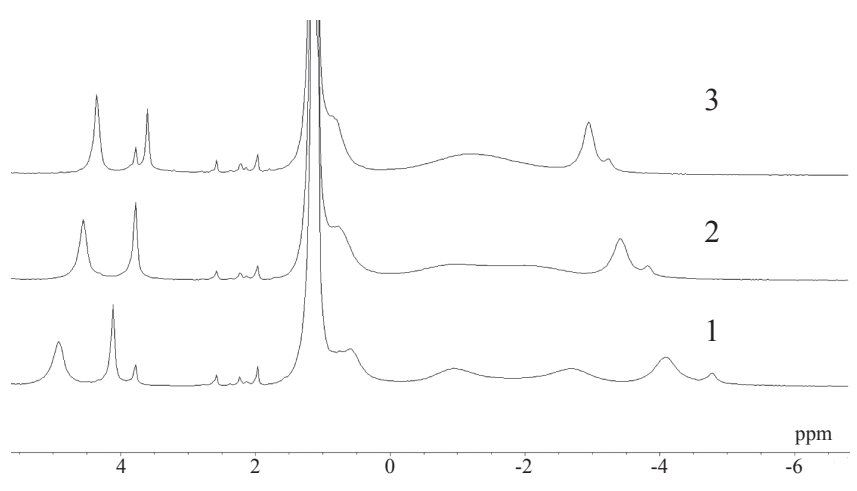

Figure 3. Variable temperature dependence of $500 \mathrm{MHz}{ }^{1} \mathrm{H}$ NMR spectra of $\left[\left(\mathrm{Ce}(\mathrm{ptfa})_{3}\right)_{2}\left(18\right.\right.$-crown-6)] in $\mathrm{CDCl}_{3}$ at 265 (1), 280.4 (2) and $290.7 \mathrm{~K}$ (3); chemical shifts values are relative to TMS.

\section{Intramolecular Dynamics}

By ${ }^{1} \mathrm{H}$ NMR method the conformational reorientation of the 18-crown-6 ether molecules in $\left[\left(\mathrm{Ce}(\mathrm{ptfa})_{3}\right)_{2}(18-\right.$ crown-6)] complexes has been experimentally studied. The 18 -crown-6 ether molecule reorientation process is attended by effective exo and endo $\mathrm{H}$ atoms in 18-crown- 6 molecules exchange (Figure 3). As one can see from the Figure 3 at low temperatures in the NMR spectrum there is a doublet, which corresponds to slow exchange, and while rising the temperature it passes the coalescence point (at $280.4 \mathrm{~K}$ ) in the range of intermediate chemical exchange rates. At high temperature, what corresponds to the case of fast exchange, the doublet transforms into the singlet. Moreover, the significant chemical shift temperature dependence is observed. In the hypothetical case of temperature dependence absence at high temperatures (for example at $290.7 \mathrm{~K}$ ) one would find the $\mathrm{CH}_{2}$ group singlet signal at $-1.75 \mathrm{ppm}$ (the centre of doublet at $265 \mathrm{~K}$ ), instead of observing signal displacement to the value $-1.10 \mathrm{ppm}$.

The schematic representation of the complex dynamics is illustrated in Scheme 1. The rate of intramolecular dynamics for $\left[\left(\mathrm{Ce}(\mathrm{ptfa})_{3}\right)_{2}(18\right.$-crown-6)] complex was determined from the measurements of the temperature dependence of its ${ }^{1} \mathrm{H}$ NMR spectra. This dependence was taken into account during the investigation of intramolecular dynamics. ${ }^{1} \mathrm{H}$ NMR signals corresponding to endo and exo protons are broadened with an increase in temperature that

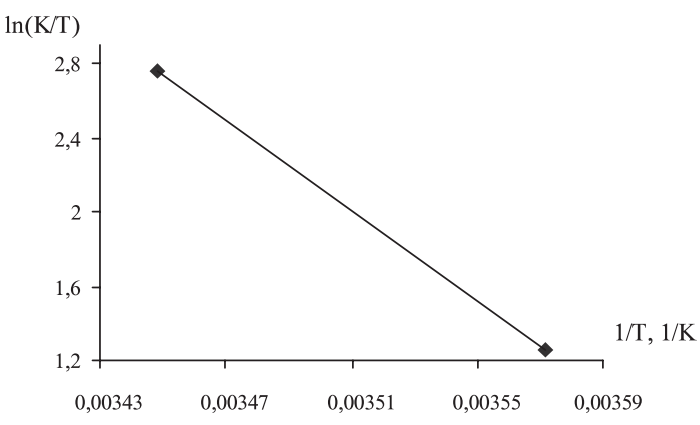

Figure 4. Dependence of $\ln (k / \mathrm{T})$ on $1 / \mathrm{T}$, where $k$ is the rate constant of the 18-crown-6 molecular dynamic process in $\left[\left(\mathrm{Ce}(\mathrm{ptfa})_{3}\right)_{2}(18-\right.$ crown-6)], $\mathrm{T}$ is the temperature, and $\mathrm{CDCl}_{3}$ as the solvent.

is consistent with (18-crown-6) molecule reorientation (proposed molecular structure is shown at Scheme 1).

As it was mentioned in the Introduction the system component interaction is well described by the thermodynamic equations system, which referred well to Eu complexes. In Ce complexes it is considered, that component interaction system is described by the analogous equations system. Besides it is considered, that the thermodynamic interaction constant value for $\mathrm{Ce}$ is close enough to that value for $\mathrm{Eu}$ or may be even slightly more because of Ce possible larger coordinate number compared to that for $\mathrm{Eu}$. It should be noted, that in the complexes the additional coordinate bonds between oxygen atoms of $\beta$-diketon chelate and other Ce cations can be formed. The activation free energy of the intramolecular 18-crown-6 ring reorientation for $\left[\left(\mathrm{Ce}(\mathrm{ptfa})_{3}\right)_{2}(18\right.$-crown-6)] were found to be $\Delta G^{\ddagger}(298 \mathrm{~K})=49 \pm 4 \mathrm{~kJ} / \mathrm{mol}$ (see Figure 4 ). We have also calculated the free energy of activation $\Delta G^{\ddagger}(320 \mathrm{~K})=45$ $\pm 4 \mathrm{~kJ} / \mathrm{mol}$ in $\left[\left(\mathrm{Ce}(\mathrm{ptfa})_{3}\right)_{2}(18\right.$-crown-6)] at $320 \mathrm{~K}$ in order to compare it with the data previously reported for another 18-crown-6 complexes with lanthanides. ${ }^{[18,25,29]}$ The found $\Delta G^{\ddagger}(320 \mathrm{~K})$ values for 18 -crown-6 reorientation are comparable with the relative values for 18 -crown- 6 macrocycle inversion process in $\left[\mathrm{Ln}\left(18\right.\right.$-crown-6) $\left.\left(\mathrm{NO}_{3}\right)_{3}\right]$ complexes (here $\mathrm{Ln}=\mathrm{Ce}, \mathrm{Pr}$, and Nd) and are slightly less than $\Delta G^{\ddagger}(320 \mathrm{~K})$ of 18-crown-6 molecular inversion process in [ $\operatorname{Ln}(18$-crown-6) $\left.(\mathrm{ptfa})_{2}\right]^{+}\left[\mathrm{Ln}(\mathrm{ptfa})_{4}\right]^{-} \mathrm{nH}_{2} \mathrm{O}$ (where $\mathrm{Ln}=\mathrm{Ce}, \mathrm{Pr}, \mathrm{Nd}$ and $\mathrm{Eu}$ ). ${ }^{[18,25]}$ At the same time the $\Delta G^{\ddagger}$ value exceeds the 18-crown- 6 molecule conformational pseudorotation energy barrier in $\left[\mathrm{Ln}\left(18\right.\right.$-crown-6) $\left.\cdot\left(\mathrm{NO}_{3}\right)_{3}\right]$.

\section{Temperature Dependence of LIS}

The LIS changes dependent on 1/T are shown in Figures 1 and 2. As one can see, in the range of the temperatures LIS for different ligand groups can be approximated by linear dependence on $1 / \mathrm{T}$.

The analysis of the temperature dependence of paramagnetic lanthanide-induced shifts in Figures 1 and 2 shows that the Curie-Weiss approximation ${ }^{[18,25]}$

$$
\Delta \delta_{\text {LIS }}=\mathrm{a}+\mathrm{b} / \mathrm{T}
$$

is good for the complex studied (like for $[\operatorname{Ln}(18$-crown-6) (ptfa) $]_{2}^{+}\left[\mathrm{Ln}(\mathrm{ptfa})_{4}\right]^{-} \cdot \mathrm{nH}_{2} \mathrm{O}, \quad\left[\mathrm{Ln}\left(18\right.\right.$-crown-6)($\left.\left(\mathrm{NO}_{3}\right)_{3}\right] \quad$ and $\left.[\operatorname{Ln}(\mathrm{EDTA})]\{\mathrm{Ln}=\operatorname{Pr} \text { and Ho for the latter complexes }\}^{[18,25]}\right)$. 
We propose to use this temperature dependence of paramagnetic LISs in NMR spectra to detect the temperatures of the samples placed directly in an NMR spectrometer in both aqueous and nonaqueous media. ${ }^{[18,29,30]}$ Complexes $\left[\left(\mathrm{Ce}(\mathrm{ptfa})_{3}\right)_{2}(18\right.$-crown-6)] can be in particular the promising subnanoscale NMR spectroscopic probes to determine the temperature in nonaqueous media. These effects are prospective for applications (of Ln complexes) as thermometric NMR sensors directly in reaction media (for in situ studies of exothermic or endothermic processes) and also in medical magnetic resonance tomography for in vivo threedimensional mapping of the body-temperature distribution and the temperature of different body parts in diseases, including some related to cancer. ${ }^{[18,25]}$
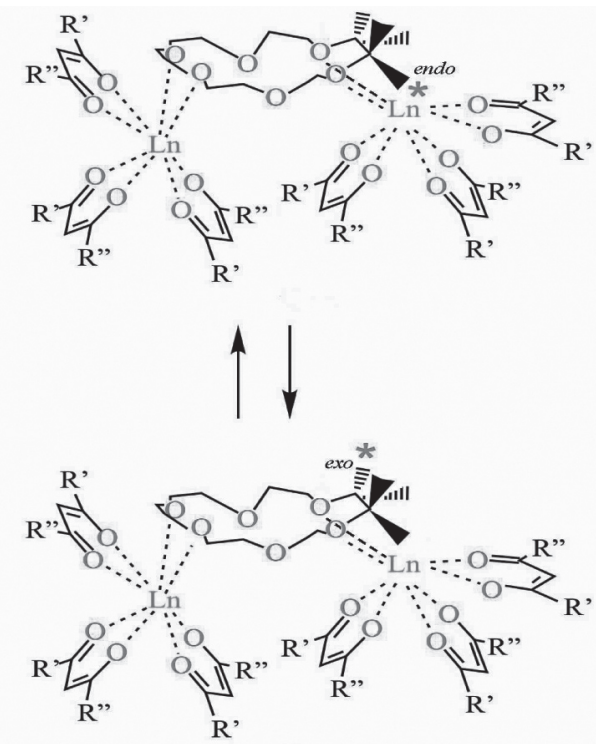

Scheme 1.

\section{Conclusions}

$\left[\left(\mathrm{Ce}(\mathrm{ptfa})_{3}\right)_{2}(18\right.$-crown-6)] has the concentration enough to be detected in the ${ }^{1} \mathrm{H}$ NMR spectra. The results of the present work demonstrate that there is a conformational dynamic processes in $\left[\left(\mathrm{Ce}(\mathrm{ptfa})_{3}\right)_{2}(18\right.$-crown-6)] complex (with the activation free energy $\Delta G^{*}(320 \mathrm{~K})=49 \pm 4 \mathrm{~kJ} /$ $\mathrm{mol})$. It is conditioned by conformational reorientation of 18-crown-6 molecule. These complexes are promising to be subnanoscale NMR spectroscopic probes to determine the temperature in nonaqueous media. The line-shape analysis, taking into account the temperature dependence of the paramagnetic chemical shift (within the framework of dynamic NMR technique) is distinguished for effective investigation of intramolecular dynamics in substrate molecules of paramagnetic lanthanide complexes.

Acknowledgements. The work was fulfilled with the financial support of the Russian Foundation for Basic Research (Grant N11-03-00197-a).

\section{References}

1. Hiraoka M. Crown Compounds: Their Characteristics and Applications. Tokyo: Elsevier. 1982.

2. Babailov S.P., Krieger Yu.G. Russ. J. Struct. Chem. 1998, 39, 714-730.

3. Martynova T.N. Protsessy rosta poluprovodnikovykh kristallov $i$ plyonok [Growth of Semiconductor Crystals and Films]. Novosibirsk: Nauka. 1988 (in Russ.).

4. Van Nostrum C.F., Nolte R.J.M. J. Chem. Soc. Chem. Commun. 1996, 2385-2392.

5. Pedersen C.D., Frenedorf H.L. Russ. Chem. Rev. 1973, 42, 492-510 (in Russ.).

6. Babailov S.P., Krieger Yu.G., Gabuda S.P. Izv. Akad. Nauk SSSR, Ser. Khim. 1990, 11, 2661-2662 (in Russ.).

7. Babailov S.P., Nikulina L.D., Krieger J.H. J. Inclusion Phenom. Macrocycl. Chem. 2002, 43, 25-29.

8. Babailov S.P., Mainichev D.A. J. Inclusion Phenom. Macrocycl. Chem. 2002, 43, 187-193.

9. Jacques V., Desreux J.F. Inorg. Chem. 1994, 33, 4048-4053.

10. Babailov S.P., Krieger Yu.G. Russ. J. Struct. Chem. 2001, 42, 373-377.

11. Yatsimirsky K.B., Davidenko M.K., Bidzilya V.A., Golovkova L.P. Stroenie, svostva i primenenie beta-diketonatov metallov [Structure, Properties and Application of Metal BetaDiketonates]. Moskva: Nauka. 1978.

12. Babailov S.P. Prog. Nucl. Magn. Reson. Spectrosc. 2009, 54, 183-194.

13. Babailov S.P., Krieger Yu.G. Russ. J. Struct. Chem. 1993, 33, 156-159.

14. Babailov S.P., Krieger J.H., Martynova T.N., Nikulina L.D. Zh. Strukt. Khim. 1990, 31, 44-47 (in Russ.).

15. Rigault S., Piguet C. J. Am. Chem. Soc. 2000, 122, 93049305.

16. Harman M.E., Hart F.A., Hursthouse M.B., Moss G.P., Raithby P.R. J. Chem. Soc., Chem. Commun. 1976, 396.

17. Backer-Dirks J.D., Cook J.E., Galas A.M.R., Ghotra C.J., Hart F.A., Hurst M.B. J. Chem. Soc., Dalton Trans. 1980, 2191.

18. Babailov S.P. Prog. Nucl. Magn. Reson. Spectrosc. 2008, $1,1$.

19. Rigault S., Piguet C., Bunzli J.C.G. J. Chem. Soc., Dalton Trans. 2000, 2045.

20. Parker D., Dickins R.S., Puschmann H., Crossland C., Howard J.A.K. Chem. Rev. 2002, 102, 1977.

21. Voronov V.K. Rus. Chem. Rev. 2010, 79, 835.

22. Babailov S.P., Coutsolelos A.G., Dikiy A., Spyroulias G.A. Eur. J. Inorg. Chem. 2001, 1, 303.

23. Danilovich S.P., Zakzhevskii V.G., Voronov V.K. Zh. Strukt. Khim. 1986, 27, 163-165 (in Russ.).

24. Babailov S.P., Krieger Yu.G. Russ. J. Struct. Chem. 2000, 41, 657-659.

25. Babailov S.P., Mainichev D.A., Nikulina L.D., Petrova S.S. J. Inclus. Phenom. 2005, 51, 73.

26. Riehemann K., Schneider S.W., Luger T.A., Godin B., Ferrari M., Fuchs H. Angew. Chem., Int Ed. 2009, 48, 872-897.

27. Godin B., Sakamoto J.H., Serda R.E., Grattoni A., Boumarini A., Ferrari M. Trends Pharmacol. Sci. [TiPS] 2010, 31, 199205.

28. Tanaka T., Mangala L.S., Vivas-Mejia P.E., Nieves-Alicea R., Mann A.P., Mora E., Han H.-D., Shahzad M.M.K., Liu X., Bhavane R., Gu J., Fakhoury J.R., Chiappini C., Lu C., Matsuo K., Godin B., Stone R.L., Nick A.M., Lopez-Berestein G., Sood A.K,. Ferrari M. Cancer Res. 2010, 70, 3687-3696.

29. Babailov S.P. Inorg. Chem. 2012, 51, 1427-1433.

30. Babailov S.P. Macroheterocycles 2010, 3, 209. 